\title{
Combined laparoscopic-assisted nephrectomy and complete mesocolic excision for synchronous renal and colon cancers
}

\author{
M O'Sullivan, ${ }^{1}$ D E Kearney, ${ }^{1}$ S K Giri, ${ }^{2}$ J C Coffey ${ }^{1,3}$
}

${ }^{1}$ Department of Surgery, University Hospital Limerick, Limerick, Ireland

${ }^{2}$ Department of Urology, University Hospital Limerick, Limerick, Ireland ${ }^{3}$ Department of Centre for Interventions in Infection, Inflammation and Immunity, Graduate Entry Medical School, University of Limerick, Limerick, Ireland

\section{Correspondence to} Dr M O'Sullivan,

osullimu@tcd.ie

Accepted 5 September 2015

\section{SUMMARY}

Cancers of the colon and kidney are common malignancies, however, the occurrence of primary synchronous neoplasms of these two organs is uncommon. To the best of our knowledge, this is the first case report of a laparoscopic radical left nephrectomy and extended right complete mesocolic excision (CME) for a patient with synchronous renal and colon cancers. While a radical nephrectomy has long been the standard of care for a renal malignancy, CME has only recently been used. Combined surgeries provide the patient with various benefits such as decreased hospital stay, less postoperative pain and morbidity, early return to work and better cosmoses.

\section{BACKGROUND}

Cancers of the colon and kidney are common malignancies, however, the occurrence of primary synchronous neoplasms of these two organs is uncommon. To the best of our knowledge, this is the first case report of a laparoscopic radical left nephrectomy and extended right complete mesocolic excision (CME) for a patient with synchronous renal and colon cancers.

\section{CASE PRESENTATION}

We report the case of a 73-year-old man who presented with asymptomatic iron-deficient anaemia. His history included type 2 diabetes mellitus, and he had a positive family history of colon cancer.

\section{INVESTIGATIONS}

Urgent colonoscopy revealed a malignant appearing ulcerated tumour in the mid-transverse colon. Multiple biopsies were performed and the histology demonstrated a moderately differentiated invasive tubular adenocarcinoma.

A staging computerised axial tomographic (CT) of the thorax, abdomen and pelvis was performed. This demonstrated a large $8 \mathrm{~cm}$ lobulated mass arising from the anterior midportion of the left kidney, in keeping with a renal cell tumour (figures 1 and 2). No other primary malignancies were identified and there was no evidence of renal or colonic metastases. The patient was discussed at the oncology multidisciplinary conference and a combined radical left nephrectomy with extended right mesocolectomy was recommended.

\section{TREATMENT}

Operative procedure

The laparoscopic radical left nephrectomy was performed first. The patient was placed in the supine position and the laparoscopic ports were inserted (Covidien, Ireland). These included a $12 \mathrm{~mm}$ epigastric, $12 \mathrm{~mm}$ left flank and $5 \mathrm{~mm}$ left upper flank port. Intra-abdominal adhesions were encountered and separated. These occurred between the greater omentum and the anterior abdominal wall in the left iliac fossa, and also between the small intestinal mesentery and the caudal surface of the transverse mesocolon. A large left renal tumour and a midtransverse colonic tumour were identified. The left colon and splenic flexure were mobilised first to gain access to the left kidney. The kidney was dissected free from the retroperitoneum, and mobilised medically along with accompanying adrenal gland and lymphatic tissue. The renal pedicle was transected intracorporeally using an endoscopic $60 \mathrm{~mm}$ linear stapler (Covidien). The kidney, together with the surrounding lymph nodes and adipose tissue, was placed into an endoscopic retrieval bag and left in situ. The extended right mesocolectomy was performed next. In the lithotomy position, a further $12 \mathrm{~mm}$ port was inserted in the right iliac fossa. The patient was placed steep head down and right shoulder up. The ileocaecal peritoneal fold was divided and this peritonotomy carried cephalad onto the right paracolic peritoneal fold. The patient was placed head up exposing the hepatocolic ligament, which was divided. This peritonotomy was continued laterally and distally and joined with the distal peritonotomy. The colofascial

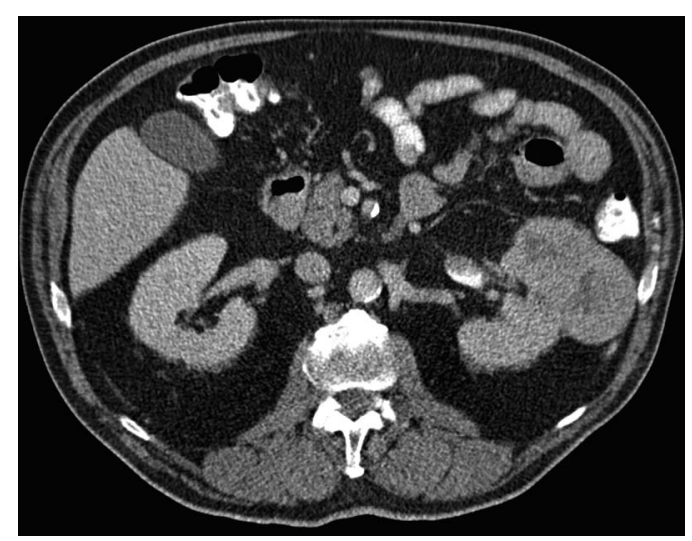

Figure 1 Abdominal CT scan demonstrating renal cell carcinomas. 


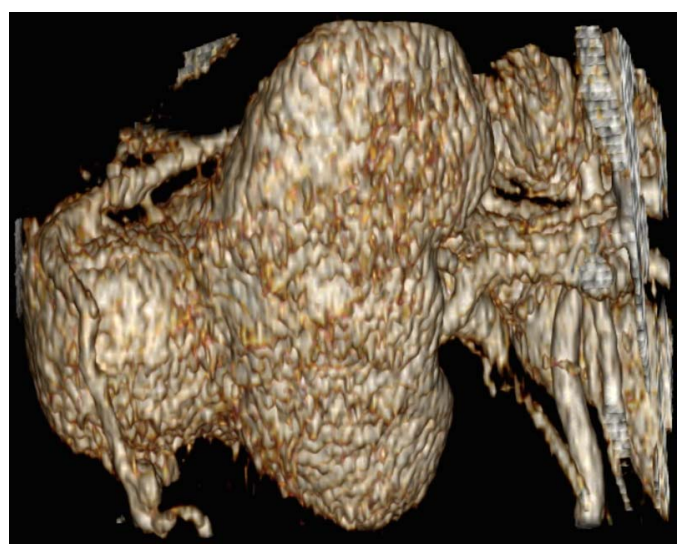

Figure 2 A three-dimensional reconstruction of renal cell carcinomas from CT imaging.

and myofascial plane components were separated, thereby medialising the colon. The greater omentum was separated off the hepatocolic fold (cephalad) and the transverse mesocolon and colon were mobilised as far medially as was feasible. As the splenic flexure had already been mobilised during the nephrectomy, the entire transverse colon and mesocolon were therefore mobilised.

The fold at the base of the small intestinal mesentery was divided and the mesofascial plane separated, thereby lifting the small intestinal mesentery off the inferior vena cava and mobilising it fully up to the third part of the duodenum. As considerable right mesocolic adiposity was present, and it was felt to be unsafe to gain intracorporeal control of the ileocolic and right colic vascular pedicles, this vascular ligation was performed extracorporeally. A $5 \mathrm{~cm}$ extraction site laparotomy was made in the epigastrium and the kidney extracted through this (figure 3). The colon was then exteriorised and the greater omentum dissected fully of the entire cephalad aspect of the transverse mesocolon, thus completing the mobilisation of this (figure 4).

The terminal ileum and colon (proximal descending) were then divided using a linear stapling device (GIA $60 \mathrm{~mm}$, Covidien), and staple lines inverted with interrupted 3-0 Vicryl (Ethicon, Ireland). The major vascular pedicles were then skeletonised taking the middle colic and the ileocolic at their origin. Mesenteric stumps were suture ligated with 0 Vicryl.

A side-to-side (ileum to descending colon) anastomosis was fashioned in a hand sewn manner in two layers, with 3-0 PDS (Ethicon). The colon was returned intraperitoneally, haemostasis

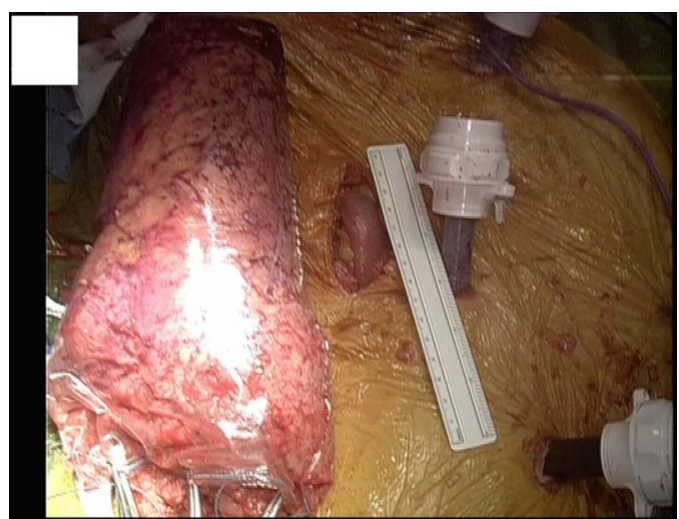

Figure 3 Nephrectomy specimen in collection bag.

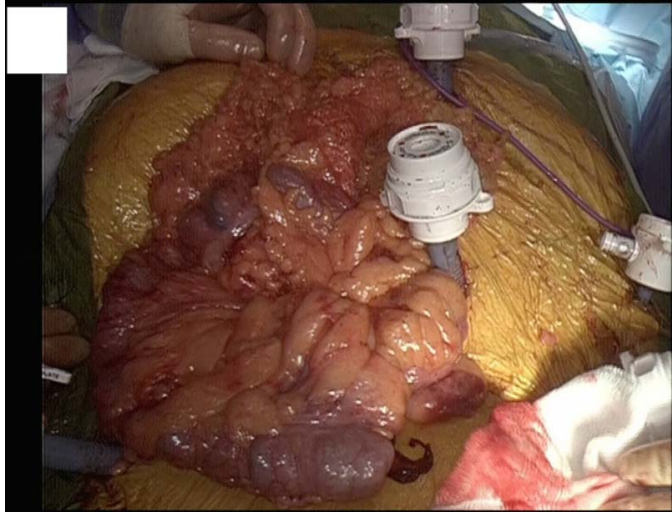

Figure 4 Exteriorised colon.

was confirmed and a Robinson drain placed in the subphrenic position on the left. Closure was completed in layers with 1 PDS and 3-0 Monocryl (Ethicon).

\section{OUTCOME AND FOLLOW-UP}

Postoperatively, pain was controlled using morphine-based patient-controlled analgesia and regular intravenous paracetamol. The subphrenic drain was removed on day 7 and the patient was discharged home on day 10 following an uncomplicated postoperative period.

Postoperative histological examination confirmed hybrid renal carcinoma with a major component of clear cell carcinoma and a minor component of solid-variant papillary carcinoma, limited to the kidney. The rest of the left kidney and urinary tract were without histopathological changes of significance. A moderately differentiated invasive tubular adenocarcinoma of colon (25 $\mathrm{mm})$, on adenomatous changes with high-grade dysplasia, with infiltration of the subserosal tissue and clear resection margins, was identified in the colonic specimen. Eighteen pericolic lymph nodes were isolated without evidence of tumour metastasis.

\section{DISCUSSION}

Synchronous primary malignant neoplasms are defined by Kim et $a l^{1}$ as a secondary malignancy occurring at the same time or within 6 months after the first malignancy. The incidence of synchronous renal and colorectal cancer is uncommon and has been variously reported with percentages ranging from $0.4 \%$ to $4.85 \% .^{2}{ }^{3}$ To the best of our knowledge, this is the first published case report of a combined laparoscopic radical nephrectomy and extended right hemicolectomy with CME. While a radical nephrectomy has long been the standard of care for a renal malignancy, CME has only recently been recognised as a superior oncological resection to a standard colonic resection. Culligan $e t ~ a l^{4}$ have described the mesocolic anatomy, which has rationalised the technique of CME. In CME, planar dissection, combined with high vascular ligation, produces a specimen with intact fascial layers while simultaneously maximising lymph node yield. ${ }^{5}$ CME is associated with significantly improved disease-free survival compared with conventional colon resections. ${ }^{6}$ It is also a significant independent predictive factor for improved disease-free survival for all patients. ${ }^{6}$ Application of this technique in dedicated centres has resulted in reduced local 5 -year recurrence rates from $6.5 \%$ to $3.6 \%$, and improved cancer-specific 5 -year survival rates from $82.1 \%$ to $89.1 \%$. 
Combined surgeries provide the patient with various benefits such as decreased hospital stay, less postoperative pain and morbidity, early return to work and better cosmesis. ${ }^{8}{ }^{9}$ Lai et al ${ }^{10}$ report average hospital length of stay for patients 70 years and older postlaparoscopic nephrectomy as 3.6 days. Patients undergoing CME have a length of stay from 3 to 5 days. ${ }^{11}$ While our case does not demonstrate reduced length of stay, our patient was discharged on day 10 , with no significant addition in hospital stay. This combined approach also appears to be costeffective to both the patient and the hospital services, as the patient requires less time off work and the hospital can utilise operating time and hospital beds more efficiently. Performing both surgeries in a combined procedure can also provide technical benefits to the operating surgeons. In our current case, because mobilisation of the splenic flexure was an essential component of the radical nephrectomy, this rendered the mobilisation of the transverse mesocolon technically easier. Performing the radical nephrectomy first therefore facilitated the CME.

\section{Learning points}

- Combined surgeries provide the patient with various benefits such as decreased hospital stay, less postoperative pain and morbidity, early return to work and better cosmesis.

- Performing both surgeries in a combined procedure can provide technical benefits to the operating surgeons. In our current case, because mobilisation of the splenic flexure was an essential component of the radical nephrectomy, this rendered the mobilisation of the transverse mesocolon technically easier.

- This combined approach also appears to be cost-effective to both the patient and the hospital services, as the patient requires less time off work and the hospital can utilise operating time and hospital beds more efficiently.
Although the risk of patient complications theoretically increases with combined cases, we believe that, in this case, the risk was justified as the overall complication rates for both procedures are low, and the patient benefited from having a combined oncological resection in a single setting.

Acknowledgements The authors would like to acknowledge Mr Dara Walsh for his contribution with the images.

Contributors The case report was written by MO with input from DEK and SKG, and edited by JCC.

Competing interests None declared.

\section{Patient consent Obtained.}

Provenance and peer review Not commissioned; externally peer reviewed.

\section{REFERENCES}

1 Kim JW, Han JW, Jung SY, et al. Synchronous double primary malignant tumor of the gallbladder and liver: a case report. World J Surg Oncol 2011;9:84.

2 Capra F, Scintu F, Zorcolo L, et al. Synchronous colorectal and renal carcinomas. Is it a definite clinical entity? Chir Ital 2003;55:903-6.

3 Halak M, Hazzan D, Kovacs Z, et al. Synchronous colorectal and renal carcinomas: a noteworthy clinical entity. Report of five cases. Dis Colon Rectum 2000;43:1314-15.

4 Culligan K, Coffey JC, Kiran RP, et al. The mesocolon: a prospective observational study. Colorectal Dis 2012;14:421-30.

5 Sehgal R, Coffey JC. Historical development of mesenteric anatomy provides a universally applicable anatomic paradigm for complete/total mesocolic excision. Gastroenterol Rep (Oxf) 2014;2:245-50.

6 Bertelsen CA, Neuenschwander AU, Jansen JE, et al. Disease-free survival after complete mesocolic excision compared with conventional colon cancer surgery: a retrospective, population-based study. Lancet Oncol 2015;16:161-8.

7 Hohenberger W, Weber K, Matzel K, et al. Standardized surgery for colonic cancer: complete mesocolic excision and central ligation-technical notes and outcome. Colorectal Dis 2009;11:354-64.

8 Ghidirim GHD, Gladun EV, Danch AV, et al. Combined laparoscopic treatment of polycystic ovary disease and gallstones J Am Assoc Gynecol Laparosc 1996;3(Suppl 4):515.

9 Wadhwa A, Chowbey PK, Sharma A. Combined procedures in laparoscopic surgery. Surg Laparosc Endosc Percutan Tech 2003;13:382-6.

10 Lai FC, Kau EL, Ng CS, et al. Laparoscopic nephrectomy outcomes of elderly patients in the 21st century. J Endouro 2007;21:1309-13.

11 Adamina M, Manwaring ML, Park KJ, et al. Laparoscopic complete mesocolic excision for right colon cancer. Surg Endosc 2012;26:2976-80.

Copyright 2015 BMJ Publishing Group. All rights reserved. For permission to reuse any of this content visit http://group.bmj.com/group/rights-licensing/permissions.

BMJ Case Report Fellows may re-use this article for personal use and teaching without any further permission.

Become a Fellow of BMJ Case Reports today and you can:

- Submit as many cases as you like

- Enjoy fast sympathetic peer review and rapid publication of accepted articles

- Access all the published articles

- Re-use any of the published material for personal use and teaching without further permission

For information on Institutional Fellowships contact consortiasales@bmjgroup.com

Visit casereports.bmj.com for more articles like this and to become a Fellow 